\title{
The Effect of Functional Group Content on Poly(ethylene terephthalate)/High Density Polyethylene Blends Compatibilized with Poly(ethylene-co-acrylic acid)
}

\author{
Sanghyo KIM, Chan Eun PARK, ${ }^{*}$ Jeong Ho An, ${ }^{* *, \dagger}$ \\ Doosung LEE, ${ }^{* *}$ and Jinhwan KIM** \\ Samyang Group R\&D Center, 63-2 Yusung-Gu, Daejeon, Korea \\ *Pohang University of Science and Technology, Department of Chemical Engineering, \\ P.O. Box 125, Pohang, Korea \\ ** Sung Kyun Kwan University, Department of Polymer Science and Engineering. \\ Kyungi-Do, Suwon-Si, Chunchun-Dong 300, Korea, 135-790
}

(Received October 11, 1996)

\begin{abstract}
The mechanical, thermal, and morphological behavior of poly(ethylene terephthalate)/high density polyethylene (PET/HDPE) blends with/without poly(ethylene-co-acrylic acid) (PEAA) as a reactive compatibilizer were investigated. The addition of PEAA improves the mechanical properties such as flexural yield strain and impact strength when HDPE forms matrix phase. On the other hand, when the PET is the matrix, no significant improvement of mechanical properties is observed, suggesting that the crystallization rate can be an important factor in the blend composed of two crystalline components. The addition of PEAA also affects morphological features such as reducing the size of the dispersed phase and making the interface obscure indicating the role of PEAA as a reactive compatibilizer. The crystallinity of PET and HDPE is slightly reduced by the addition of PEAA. The content of acrylic acid (AA) in PEAA also has an effect on mechanical properties and morphology, suggesting the added PEAA goes to the HDPE phase as well as the interface between PET and HDPE.

KEY WORDS Poly(ethylene terephthalate / High Density Polyethylene / Compatibilizer / Morphology / Mechanical Property /
\end{abstract}

Poly(ethylene terephthalate) (PET) is widely used as an engineering thermoplastic for packaging, electronics, automotives, and other applications. High density polyethylene (HDPE) is also widely used as a general purpose thermoplastic for film, pipe and injection moldings. However, PET and HDPE are major contributors to the waste stream due to being widely used as beverage bottles. Related to a recycling problem, PET/HDPE systems have been extensively studied, especially regarding compatibilization techniques, because this system is grossly incompatible and exhibits extremely poor mechanical properties without compatibilization. ${ }^{1,2}$

The major types of compatibilizers used for PET/ HDPE system are styrenic block copolymers including styrene-ethylene-butylene-styrene (SEBS) block copolymers, ${ }^{2}$ acid or maleic anhydride functionalized SEBS, ${ }^{3}$ and styrene-ethylene-propylene (SEP) block copolymer and ethylene copolymers including ethylenevinyl acetate, ethylene-acrylic acid, ethylene-methacrylate copolymers, ${ }^{5}$ and maleic anhydride graft PE. ${ }^{6}$ The results from these studies suggest the possible enhancement of properties in PET/HDPE blend by compatibilization. Especially, when MA- $g$-SEBS block copolymers of $20 \mathrm{phr}$ is used as compatibilizer, PET/HDPE blends became super tough due to the intricate multidomain morphology.

Recently, reactive compatibilization in which in-situ graft or block copolymers are formed from functional units of polymers during melt blending, has been applied to many incompatible pairs. In reactive compatibilization, the amount of functional group is the most important factor in determining the morphology and

\footnotetext{
† To whom all correspondence should be addressed.
}

mechanical properties. When the amount of functional group is insufficient, little graft or block copolymer is produced at the interface, thus it can not provide efficient compatibilization. On the other extreme, when the functional groups are more than required, the in-situ formed copolymer may have too large a molecular weight, thus it is located in the bulk phase rather than at the interface resulting in poor distribution of dispersed phase.

In most of the previous studies mentioned above, the effect of functional group content has not been investigated extensively. In this study, it was our major concern to investigate the effect of functional group content on morphology, mechanical and thermal properties while fixing the overall content of compatibilizer. As the compatibilizer, poly(ethylene-co-acrylic acid) (PEAA) with various acrylic acid (AA) contents was employed. The content of PEAA was fixed at $10 \mathrm{phr}$ which is sufficient to act as a compatibilizer. ${ }^{1}$ The acid functional group in the compatibilizer is known to be able to react with polyester through transesterification or ester exchange reaction. The ester exchange reaction is induced by residual catalyst remaining from the polyester polymerization. ${ }^{11-13}$

\section{EXPERIMENTAL}

HDPE (Daelim Ind. Co., Ltd., Trade name HDPE 6045) and PET (Kolon Ind. Inc., Kopet 185 bottle grade) were used as received. The Primacor 3150, 3340, and 3440 (Dow Chemical Co.) which is the poly(ethylene-coacrylic acid) are used as compatibilizer. These three PEAA have AA contents of 3,6,10 wt\% respectively, but have similar melt index $($ M.I. $=10)$. Samples were made at 4 different compositions of PET/HDPE; 90/10, 
$75 / 25,50 / 50$, and $25 / 75 \mathrm{wt} / \mathrm{wt}$. The amount of the compatibilizer, PEAA, was fixed at 10 parts per hundred based on PET/HDPE.

The materials as received were dried in a vacuum oven at $100^{\circ} \mathrm{C}$ for 1 day. Their blends were prepared in Brebender Plasticoder set at a wall temperature of $267^{\circ} \mathrm{C}$ and speed of $40 \mathrm{rpm}$ under a nitrogen atmosphere. The test specimens were obtained by compression molding at a plateau temperature of $270^{\circ} \mathrm{C}$ under a nitrogen atmosphere. Mechanical properties were tested with 3-point flexual test (ASTM D790) and notched Izod impact test (ASTM D265). Thermal analysis was performed with a Perkin Elmer DSC 7 at a heating rate of $20^{\circ} \mathrm{C} \mathrm{min}^{-1}$. The crystallinity in the blends was expressed as the crystallinity indices, $\chi_{\mathrm{PET}}$ and $\chi_{\mathrm{PE}}$, defined as follows.

$$
\chi_{\mathrm{PET}}=\frac{\Delta H_{\mathrm{PET}}}{\Delta H_{\mathrm{ref}}}
$$

where $\Delta H_{\text {ref }}$, heat of fusion of pure PET

$$
\Delta H_{\mathrm{PET}}=\frac{\Delta H_{\mathrm{blend}}}{1-x / 100}
$$

$\Delta H_{\text {blend }}$, heat of fusion of PET in the blend $x$, the weight percent of the other component

A scanning electron microscope, JEOL JSM-840A, was used to observe the morphology of fractured surface of compression molded specimen.

In order to compare viscosity and elasticity ratios of blends with different content of functional group, the complex viscosity $\left[\eta^{*}(\omega)\right]$, storage modulus $\left[G^{\prime}(\omega)\right]$ and loss modulus $\left[G^{\prime \prime}(\omega)\right]$ as a function of angular frequency $(\omega)$ were measured by a Rheometrics Dynamic Spectrometer (Rheometrics Co., RDS-II) using $25 \mathrm{~mm}$ parallel plates under oscilatory shear mode at $270^{\circ} \mathrm{C}$.

\section{RESULTS AND DISCUSSION}

\section{Mechanical Properties}

In order to confirm the reaction between the acid functional group in the compatibilizer and PET, the complex viscosity and elasticity ratio are compared among PET/HDPE $(50: 50)$ samples with different content of AA in the PEAA while fixing the overall content of PEAA at $10 \mathrm{phr}$. The viscosity in Figure 1 and the elasticity ratio in Figure 2 shows the increase with the increase of the AA content in the PEAA, suggesting that the acid functional group in the PEAA has been reacted with PET under the given condition of the blending process with Brabender Plasticoder.

The flexural moduli of PET/HDPE blends containing $10 \mathrm{phr}$ of PEAA are plotted as a function of HDPE content in Figure 3. Regardless of AA content in the PEAA, a negative deviation from the simple mixing rule is observed at all composition of HDPE, which is the characteristics of grossly separated systems. ${ }^{14}$ Such deviation becomes more significant as the HDPE content increased and the modulus of blends containing more than $50 \%$ of HDPE becomes rather similar to that of HDPE. As will be shown in the microphotographs, in the specimens with more than $50 \%$ of HDPE, the HDPE forms the continuous phase. The moduli of PEAA added

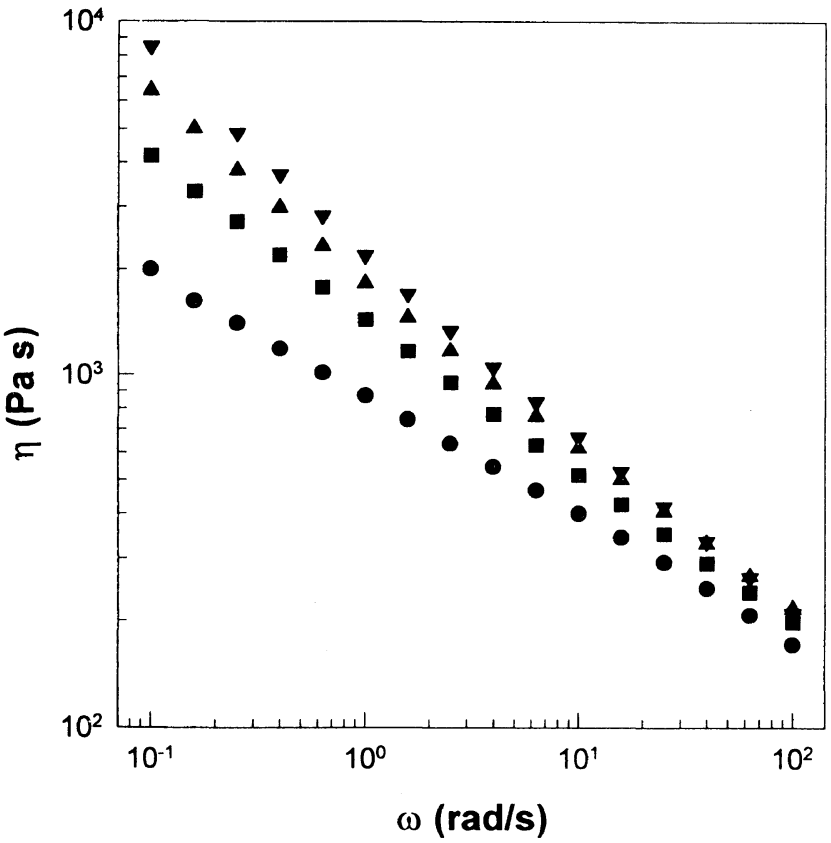

Figure 1. Viscosity of PET/HDPE (50/50) with $10 \mathrm{phr}$ of PEAA as compatibilizer. $\bullet$, without PEAA; , with PEAA containing $3 \mathrm{wt} \%$ of AA groups; $\boldsymbol{\Delta}$, with PEAA containing $6 \mathrm{wt} \%$ of AA groups; $\boldsymbol{\nabla}$, with PEAA containing $10 \mathrm{wt} \%$ of AA groups.

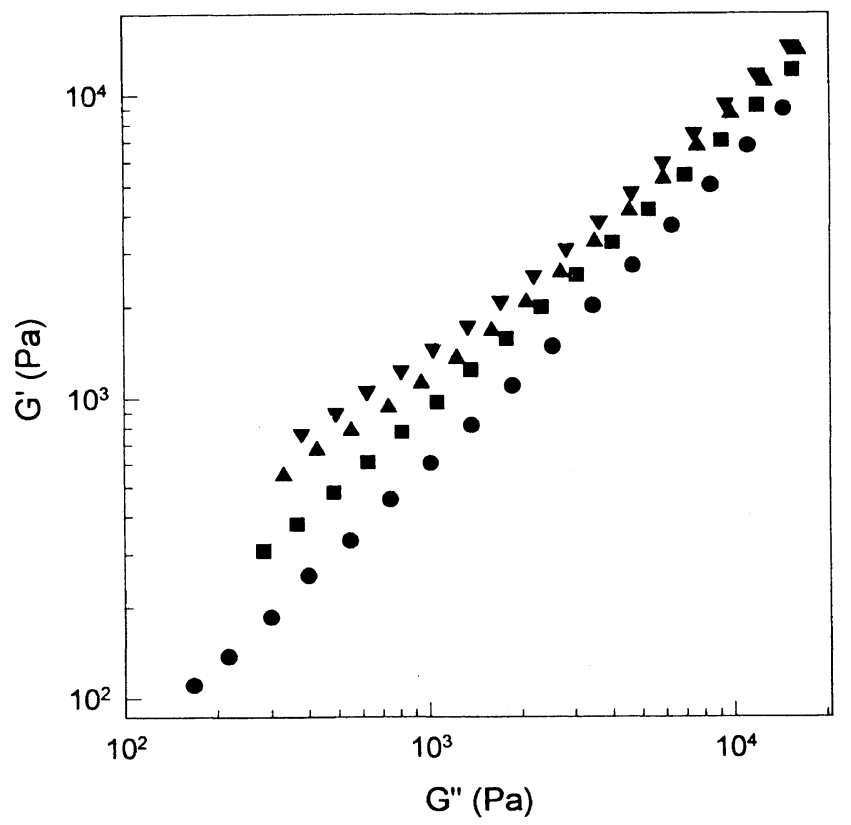

Figure 2. Elasticity of PET/HDPE (50/50) with $10 \mathrm{phr}$ of PEAA as compatibilizer. without PEAA; $\boldsymbol{\square}$, with PEAA containing $3 \mathrm{wt} \%$ of AA groups; $\boldsymbol{\Delta}$, with PEAA containing $6 \mathrm{wt} \%$ of AA groups; $\boldsymbol{\nabla}$, with PEAA containing $10 \mathrm{wt} \%$ of AA groups.

blends are found to have lower values than those of blends without compatibilizer. This seems to reflect the low modulus of the added component, PEAA. As will be discussed in the morphology section, the added PEAA seems to go to either the HDPE phase or the interface. If the entire amount of PEAA is located in the HDPE phase, a more significant reduction in modulus can be expected, especially for the specimen having HDPE as the matrix phase.

The effect of the added PEAA becomes significant when the flexural strains are compared as in Figure 4. 


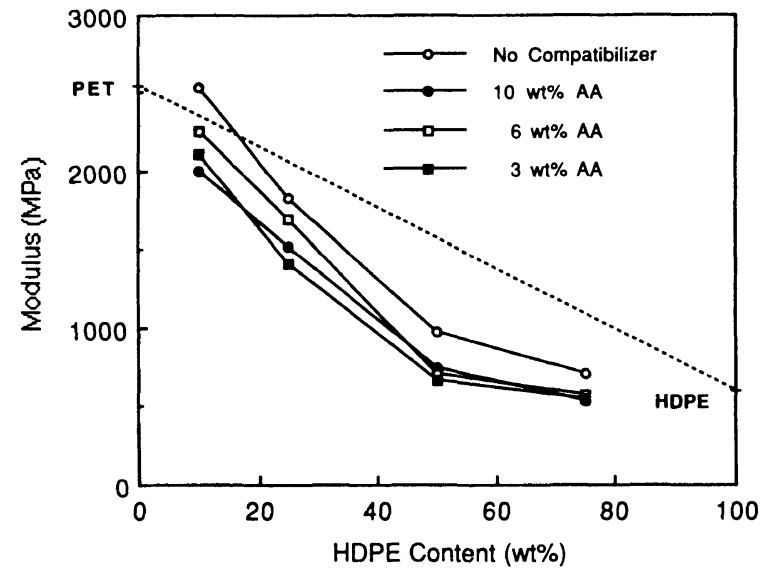

Figure 3. Flexural modulus vs. composition for PET/HDPE with/ without PEAA.

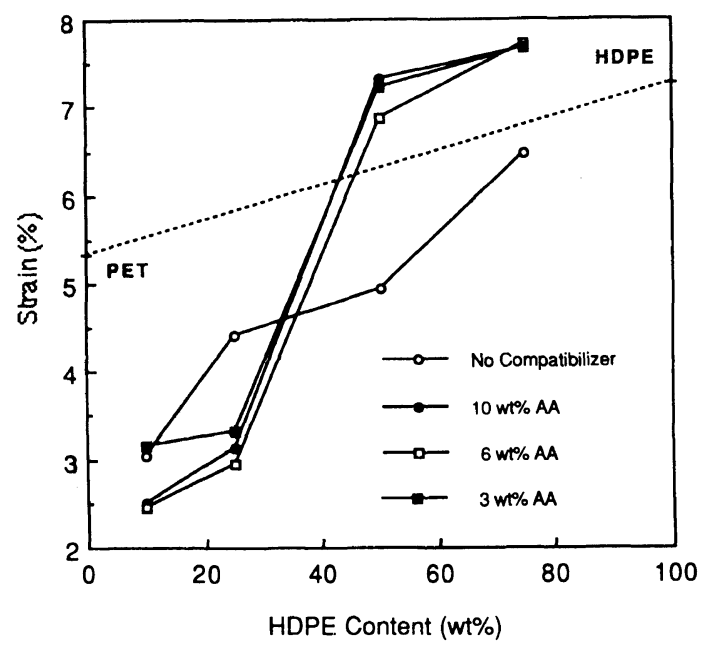

Figure 4. Flexural strain $v s$. composition for PET/HDPE with/ without PEAA.

While the blends without compatibilizer show a negative deviation from the simple mixing rule throughout the entire composition range, the PEAA added blends exhibit S-shape curves depending on HDPE contents. At the high HDPE content in which HDPE forms the continuous phase, the addition of PEAA improves the flexural strain while a negative deviation is observed for the specimen having the continuous phase of PET. This behavior can be explained in two different ways. If a considerable amount of the added PEAA goes to HDPE phase, the flexural strain will be improved for the specimen having HDPE as the matrix. On the other hand, if the PET is the matrix, the added HDPE may not have a significant effect on the strain which is mainly dependent on the nature of the matrix phase. The other possible reason could be found in the crystallization behavior of the two polymers. The crystallization rate of HDPE is much faster than that of PET. Therefore, the volume shrinkage of HDPE is higher than that of PET during the cooling period in the mold. Thus, if the PET is matrix phase, microvoids might be formed at the interface causing the reduction in the strain.

As the flexural strain becomes higher, the toughness is expected to increase. This expectation is confirmed in Figure 5 showing Impact strength as a function of HDPE content. The PEAA added specimens show better impact

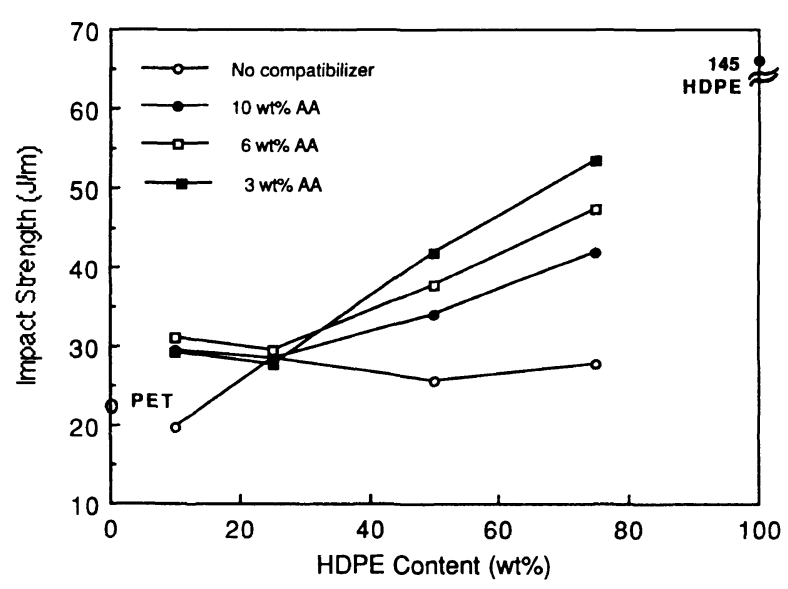

Figure 5. Impact strength vs. composition for PET/HDPE with/ without PEAA.

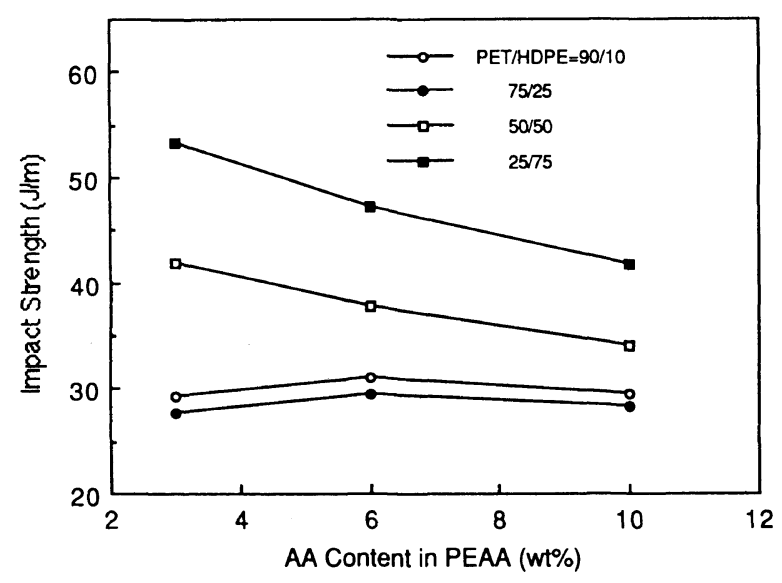

Figure 6. Impact strength $v s$. AA content in PEAA for PET/HDPE.

strength compared with the non-added specimens. When the same data is replotted as a function of AA content in the PEAA (Figure 6), the samples with the lower content of AA generally show better impact strength. Since the morphology of the specimens containing PEAA with different AA contents do not show significant differences as will be discussed later, the relative compatibility of HDPE toward the PEAA having different AA content seems to be the major factor in controlling impact strength. As the AA content increases, the compatibility of PEAA and HDPE becomes poorer. Therefore, the PEAA becomes more compatible with decreasing AA content, making the HDPE phase more ductile. On the other hand, if PET becomes the matrix phase, the difference in AA content has no effect on impact strength as seen in Figure 6.

\section{Thermal Properties}

Table I shows the $T_{\mathrm{m}}$ and crystallinity index for blends based on DSC measurements. The crystallinity is generally reduced to some extent when the PEAA is added, suggesting the added PEAA constrains the crystallization of PET and HDPE to some extent by interaction between HDPE, PET, and PEAA. On the other hand, no shift of $T_{\mathrm{m}}$ in HDPE and PET is found, indicating the added PEAA does not have an effect on the lamellar structure of HDPE or PET. The overall behavior is rather similar to that of Nylon6/PEAA blends. ${ }^{15}$ 
Effect of Functional Group on Compatibilized PET/HDPE Blends

Table I. Thermal properties for PET/HDPE with or without PEAA

\begin{tabular}{|c|c|c|c|c|c|c|}
\hline & $\Delta H_{\mathrm{HDPE}}$ & $\chi_{\text {HDPE }}$ & $\Delta H_{\mathrm{PET}}$ & $\chi_{\mathrm{PET}}$ & $T_{\mathrm{m}_{\mathrm{HDPE}}}$ & $T_{\mathrm{mPET}}$ \\
\hline HDPE & 203 & & & & 133 & \\
\hline PET & & & 38.2 & & & 253 \\
\hline \multicolumn{7}{|c|}{ No compatibilizer } \\
\hline \multicolumn{7}{|c|}{$\mathrm{PET} / \mathrm{HDPE}=$} \\
\hline $90 / 10$ & 15.5 & 76.3 & 33.9 & 98.7 & 129 & 255 \\
\hline $75 / 25$ & 40.2 & 79.1 & 23.9 & 83.4 & 131 & 254 \\
\hline $50 / 50$ & 94.8 & 93.3 & 19.0 & 99.7 & 135 & 256 \\
\hline $25 / 75$ & 147 & 96.5 & 9.8 & 102 & 133 & 255 \\
\hline \multicolumn{7}{|c|}{$3 w t \%$ AA } \\
\hline $90 / 10$ & 13.8 & 72.9 & 28.8 & 92.1 & 128 & 253 \\
\hline $75 / 25$ & 37.5 & 81.1 & 25.9 & 99.6 & 131 & 256 \\
\hline $50 / 50$ & 80.8 & 87.5 & 16.3 & 94.1 & 131 & 254 \\
\hline $25 / 75$ & 119 & 85.6 & 7.2 & 83.0 & 133 & 256 \\
\hline \multicolumn{7}{|c|}{$6 \mathrm{wt} \% \mathrm{AA}$} \\
\hline $90 / 10$ & 12.7 & 69.0 & 28.0 & 89.7 & 128 & 255 \\
\hline $75 / 25$ & 37.0 & 80.0 & 22.5 & 86.6 & 131 & 255 \\
\hline $50 / 50$ & 82.5 & 89.3 & 18.2 & 105 & 133 & 256 \\
\hline $25 / 75$ & 115 & 82.7 & 6.6 & 76.3 & 133 & 256 \\
\hline \multicolumn{7}{|c|}{$10 \mathrm{wt} \% \mathrm{AA}$} \\
\hline $90 / 10$ & 12.9 & 69.9 & 31.1 & 99.5 & 127 & 253 \\
\hline $75 / 25$ & 36.3 & 78.6 & 22.2 & 85.4 & 131 & 256 \\
\hline $50 / 50$ & 75.5 & 81.8 & 15.9 & 91.5 & 133 & 255 \\
\hline $25 / 75$ & 120 & 86.9 & 8.6 & 99.5 & 132 & 255 \\
\hline
\end{tabular}

No PEAA addition

a)

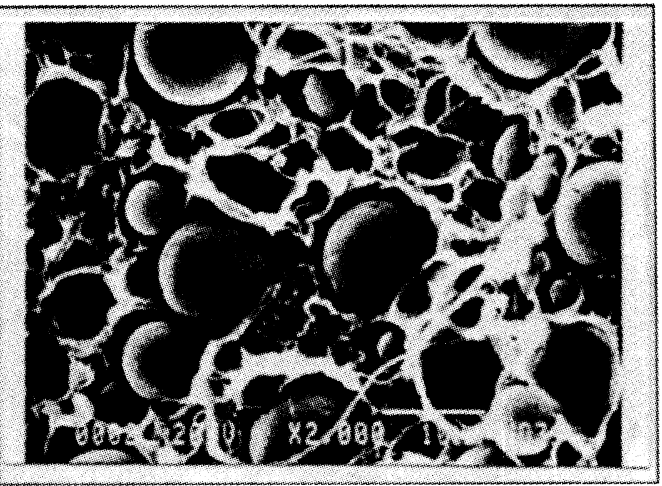

b)

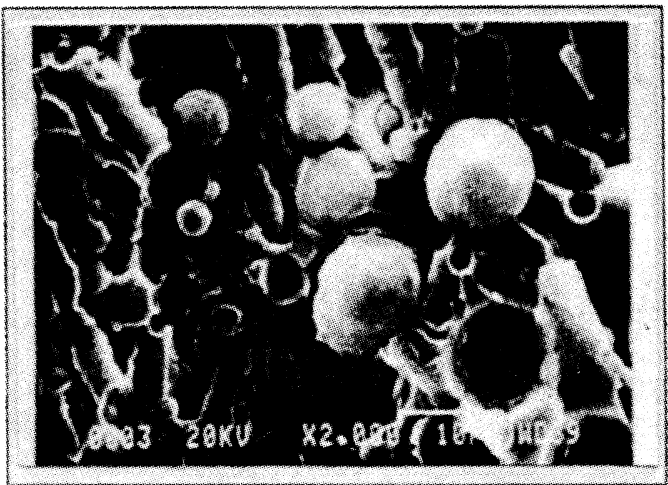

With PEAA $10 \mathrm{phr}$
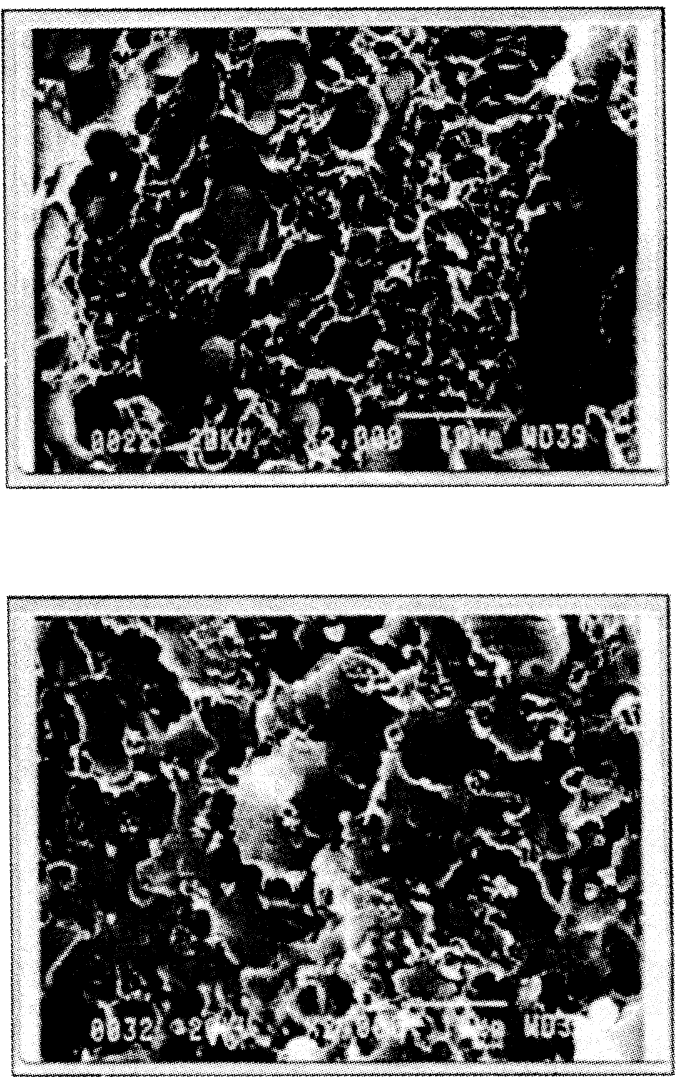

$10 \mu \mathrm{m}$

Figure 7. Scanning electron micrographs with/without PEAA (6wt \% AA). a) PET/HDPE 50/50 (wt/wt); b) PET/HDPE 75/25 (wt/wt). 
AA content in PEAA (wt \%); 3

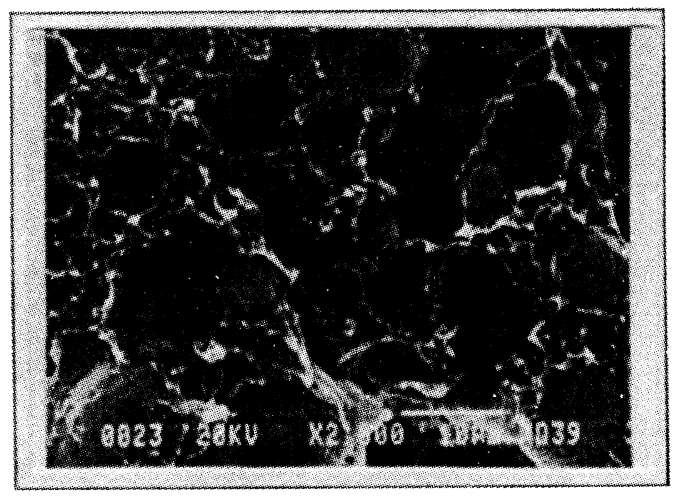

6

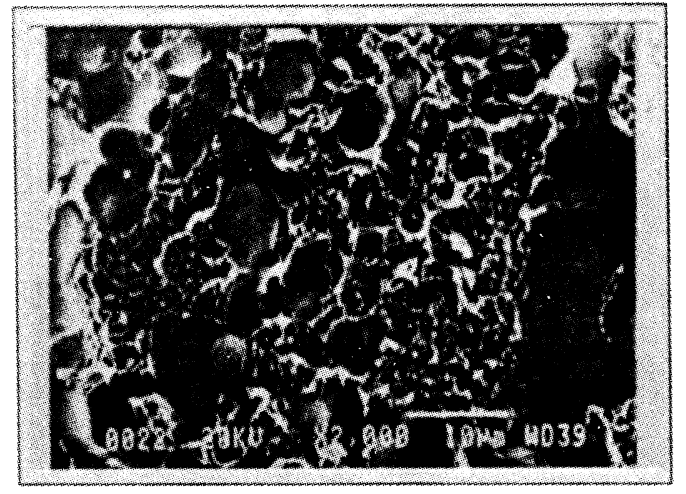

10

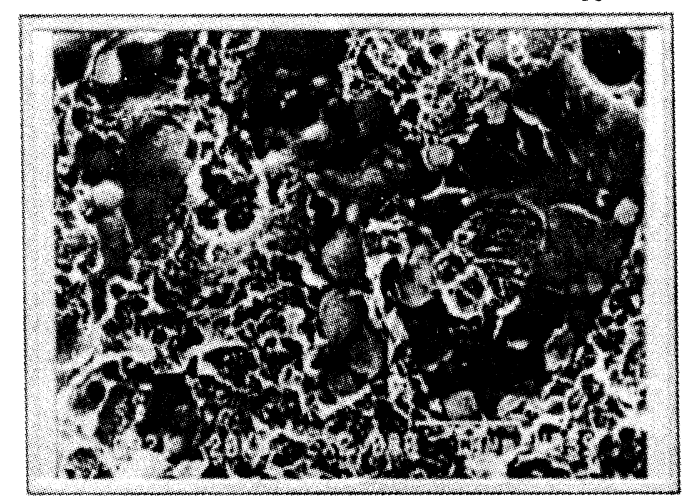

$10 \mu \mathrm{m}$

Figure 8. Scanning electron micrographs of PET/HDPE 50/50 (wt/wt) containing 10 phr PEAA with different AA contents.

\section{Morphology}

Micrographs of PET/HDPE 75/25 and 50/50 blends are compared in Figure 7 . When compared at the same HDPE content, the PEAA added sample shows much smaller domains sizes and a less definite interface, suggesting some of the added PEAA goes to the interface. The microphotograph of the blend of PET/HDPE 75/25 without PEAA shows an orange-peel appearance around the dispersed domain of PET. The origin of the orange-peel appearance may be attributed to the volume shrinkage of PET during crystallization. Similar features have been observed in poly ( $p$-phenylene sulfide $) /$ polyethylene blends. ${ }^{16}$

In the PET/HDPE $75 / 25$, in which the matrix is composed of PET and the dispersed phase is HDPE, the addition of PEAA causes size reduction of the dispersed phase. However, if the dispersed domains in PEAA added specimens are carefully observed, the dispersed domains seem to contain subdomains. These subdomains are presumably composed of PEAA, considering that the PEAA has better compatibility with HDPE than PET. Therefore a considerable amount of PEAA seems to be located in the HDPE phase as well as going to the interface. If the AA content of PEAA is varied for the PET/HDPE 50/50 specimen, the size of the dispersed phase shows slight reduction with AA content as shown in Figure 8. It is also worthwhile to note that the dispersed domains show more aggregation with the AA content increase.

\section{CONCLUSIONS}

When PEAA with different AA contents is employed as the compatibilizing agent for a PET/HDPE blend, it affects the behavior of the blend in two different ways. First, as a compatibilizing agent, it reduces the domain size. Secondly, as mixed with HDPE, it modifies the properties of the HDPE phase. The variation in AA content of PEAA mainly modifies the mechanical behavior by having different degrees of compatibility toward the HDPE phase. On the other hand, the size reduction and spatial distribution of the dispersed phase can not be explained by the compatibility between PEAA and HDPE, suggesting that some of the added PEAA plays a role of reactive compatibilizer. If the blend consists of two crystalline polymers like PET/HDPE blend, the crystallization rate can be an important factor in determining mechanical properties.

Acknowledgment. The authors are pleased to thank the Korea Science and Engineering Foundation (930300-11-01-3) for financial support.

\section{REFERENCES}

1. S. A. Jabarin, E. A. Lofgren, and S. B. Shah, in "Emerging Technologies in Plastics Recycling," G. D. Andrews and P. M. Subramanian, Ed., American Chemical Society, Washington, D C., 1992, Chapter 17.

2. T. D. Traugott, J. W. Barlow, and D. R. Paul, J. Appl. Polym. Sci., 28, 2947 (1983).

3. T. L. Carte and A. Moet, J. Appl. Polym. Sci., 48, 611 (1993).

4. J. Curry and A. Kiani, Preprints, SPE ANTEC '90, Society of Plastics Engineers, Annual Technical Conference, Dallas, Texas, May, 1990, 1452 (1990).

5. G. E. Wissler, Preprints, SPE ANTEC '90, Society of Plastics Engineers, Annual Technical Conference, Dallas, Texas, May, 1990, 1434 (1990).

6. P. Sambru and S. A. Jabrin, Polym. Eng. Sci., 33, 827 (1993).

7. F. Ide and A. Hasegawa, J. Appl. Polym. Sci., 18, 963 (1974).

8. B. D. Favis, Can. J. Chem. Eng., 69, 619 (1991).

9. M. Xanthos, Polym. Eng. Sci., 28, 1392 (1988).

10. M. Xanthos and S. S. Dagli, Polym. Eng. Sci., 31, 929 (1991)

11. A. Legros, P. J. Carreau, B. D. Favis, and A. Michel, Polymer, 35, 758 (1994).

12. F. Pilati, Polym. Eng. Sci., 23, 750 (1983).

13. G. H. Hu, J. T. Lidt, and M. J. Lambla, Appl. Polym. Sci., 36, 1039 (1992).

14. J. Kohler, G. Reiss, and A. Bandret, Eur. Polym. J., 4, 173, 187 (1968).

15. K. J. Yoon, "Blends of Nylon 6 with poly(ethylene-co-acrylic acid)," Ph. D. thesis, North Carolina State University, Rayleigh, 1989.

16. T. H. Chen and A. C. Su, Polymer, 34, 4826 (1993). 